\title{
ASPECTOS JURÍDICOS DA ECONOMIA DO COMPARTILHAMENTO: FUNÇÃO SOCIAL E TUTELA DA CONFIANÇA
}

\section{LEGAL ASPECTS OF SHARING ECONOMY: SOCIAL FUNCTION OF PROPERTY AND THE PROTECTION OF TRUST}

\author{
Carlos Affonso Pereira de Souza ${ }^{1}$ \\ Ronaldo Lemos ${ }^{2}$
}

\begin{abstract}
Resumo
A partir de algumas características essenciais da chamada economia do compartilhamento, o artigo busca traçar algumas considerações jurídicas sobre o seu desenvolvimento, buscando na principiologia constitucional e contatual elementos que reforçam aspectos positivos desse fenômeno. Destaque é dado ao princípio da função social dos bens, e em especial àquela relativa aos bens móveis, e ao princípio da boa-fé objetiva, enfatizando como iniciativas típicas da economia do compartilhamento podem incrementar a transparência e a confianças nas relações contratuais, além de gerar impactos relevantes sobre a forma de realização das mais diversas atividades nas cidades.
\end{abstract}

Palavras-Chave: Economia do Compartilhamento; Função Social; Boa-fé objetiva; Tutela da Confiança; Direito Civil; Direito da Cidade.

\section{Abstract}

This article aims to analyze a set of legal features concerning the evolution of the so-called sharing economies. In order to better understand how Law can interplay with the expansion of activities usually labeled as part of the sharing economies movement, the article suggests that the constitutional principle of social function of property as well as the strengthening of the principle of objective good faith could serve as two relevant guides to such an analysis. The compliance requirements stated in some constitutional and other legal provisions concerning the social function of property can lead to a better way to examine the impact of sharing economies activities in the cities. On other hand, the principle of objective good faith can emphasize how typical sharing economy initiatives might increase transparency and trusts in contractual relationships.

Keywords: Sharing Economy; Social Function; Property; Trust; Civil Law.

\footnotetext{
${ }^{1}$ Doutor em Direito Civil pela Universidade do Estado do Rio de Janeiro (Uerj). Pesquisador Visitante do Information Society Project, da Faculdade de Direito da Universidade de Yale. Professor Visitante nos cursos de graduação e pós-graduação stricto sensu da UERJ. Professor dos cursos de graduação e pós-graduação lato sensu da PUC-Rio e do IBMEC. Membro da Comissão de Direito Autoral da OAB/RJ (desde 2007). Conselheiro eleito do GNSO/ICANN como representante dos usuários não-comerciais da Internet (20082009) e membro do Comitê Executivo da NCUC (non-commercial users constituency). Membro do Comitê Executivo da Iniciativa por Princípios e Direitos Fundamentais na Internet, criada no Fórum de Governaça da Internet (IGF) da ONU. Fundador e coordenador do Centro de Tecnologia e Sociedade (CTS/FGV), entre 2003 e 2013. Policy Fellow da ONG Access. Conselheiro do Instituto NUPEF. Consultor do Observatório da Internet no Brasil, uma iniciativa do Comitê Gestor da Internet no Brasil (CGI.br). E-mail: caff@itsrio.org

${ }^{2}$ Doutor em Direito na Universidade do Estado de São Paulo. Diretor do Instituto de Tecnologia e Sociedade do Rio de Janeiro (ITS). Professor da Faculdade de Direito da UERJ. Pesquisador Visitante e Liaison Officer para o Brasil do MIT Media Lab. Professor Visitante da Universidade de Princeton, afiliado ao Center for Information Technology Policy. E-mail: ronaldolemos123@gmail.com
} 


\section{INTRODUÇÃO}

As formas de acesso e de utilização dos mais variados tipos de bens e serviços atravessam um período de inegáveis mudanças. Economia do compartilhamento é apenas um disputado termo que procura caracterizar esse momento de transformação que atinge o transporte e a hospedagem, o trabalho intelectual e as atividades financeiras, dentre tantos outros aspectos da vida cotidiana.

As disputas pelo melhor termo para definir as atuais transformações não devem ser um obstáculo para aprofundar as consequências jurídicas derivadas desses movimentos. Diversos são os campos de aplicação do Direito impactados pela chamada economia do compartilhamento, demandando uma nova leitura sobre as práticas e suas derivações. Contrato, propriedade e trabalho são apenas algumas das categorias jurídicas que precisam ser analisadas para que se compreenda melhor a estrutura e os impactos da economia do compartilhamento.

O objetivo deste curto artigo é passar em revista dois temas de prisma mais principiológico que podem servir de base para análises jurídicas de maior fôlego. Tomando o exemplo dos aplicativos que permitem a contratação de transporte privado, procura-se enfatizar como o desenvolvimento dessas alternativas para o deslocamento nas cidades é reforçado pelos fins que se buscam alcançar com a consagração da função social dos bens.

Em seguida, tomando por base o princípio da boa-fé objetiva nos contratos, destaca-se o papel que determinadas medidas de avaliação e transparência podem gerar para o incremento da tutela da confiança nas relações contratuais celebradas dentro de iniciativas geralmente caracterizadas como pertencentes ao fenômeno da economia do compartilhamento.

Essa análise, por fim, permite que se faça um breve comentário sobre como as diferentes iniciativas próprias da chamada economia do compartilhamento vem transformando a realização das mais distintas atividades nas cidades. As formas de medição desse impacto e os seus resultados são variados, mas é inegável o aspecto transformador de sua adoção.

\section{ECONOMIA DO COMPARTILHAMENTO}

A chamada economia do compartilhamento constitui o que diversos autores caracterizam como uma nova etapa no processo de desenvolvimento econômico, simbolizado pela superação da lógica de consumo em massa e visando ao acúmulo de bens, típica do final do último século, por um momento em que o mercado, já saturado por crises financeiras e pautado por necessidades 
ligadas à sustentabilidade e ao uso racional dos bens, passa a privilegiar novas formas de acesso a bens e a serviços. Em última instância, a economia do compartilhamento está baseada no uso de tecnologia da informação em prol da otimização do uso de recursos através de sua redistribuição, compartilhamento e aproveitamento de suas capacidades excedentes.

Ricardo Abramovay lembra que a economia do compartilhamento horizontaliza as relações humanas, "descentraliza os instrumentos de produção e troca, abre caminhos para a cooperação direta ente indivíduos (conhecidas como peer to peer ou P2P) e empresas (business to business ou B2B) e contesta o uso indiscriminado dos direitos autorais como base da inovação". Para o autor, as três principais transformações teóricas que a junção da lógica do compartilhamento com as mídias digitais possibilitam são (i) a descentralização das atividades impulsionadas pela rede; (ii) a redução dos custos de transação; e (iii) a emergência de uma economia da atração pautada na confiança existente em relações interpessoais. ${ }^{3}$

A descentralização das atividades atinge em cheio o conceito de economia de escala, evidenciando que, se na sociedade tipicamente industrial a concentração de recursos era fundamental para a eficiência econômica, o modelo que começa a ser desenhado a partir da lógica do compartilhamento privilegiaria exatamente o oposto. Os recursos, em regra, não estariam mais centralizados nas mãos de poucos, mas sim poderiam ser gerados e explorados por aqueles situados nas pontas, usando a tecnologia para aproximar demandas. ${ }^{4}$

Um exemplo direto desse cenário reside no fato de que empresas usualmente identificadas como parte da chamada economia do compartilhamento, como Uber e Airbnb, respectivamente viabilizando locomoção e acomodação nas cidades, não possuem frotas de carros ou quartos para hospedagem próprios, atuando ambas as empresas como intermediários entre os polos interessados.

\footnotetext{
${ }^{3}$ ABRAMOVAY, Ricardo. "A Economia Híbrida do Século XXI", in COSTA, Eliane; AGUSTINI, Gabriela (orgs) De Baixo para Cima. Rio de Janeiro: Aeroplano, 2014; pp. 104/131.

${ }^{4}$ Sobre o fenômeno da descentralização, lembra Yochai Benkler que o mesmo pode colocar em xeque o recurso ora ao mercado, ora ao Estado, como forma primordial de provisão de recursos. Segundo o autor: "Goods, services, and resources that, in the industrial stage of the information economy required large-scale, concentrated capital investment to provision, are now subject to a changing technological environment that can make sharing a better way of achieving the same results than can states, markets, or their hybrid, regulated industries. (BENKLER, Yochai. The Wealth of the Networks: how social production transforms markets and freedom. New Haven: Yale University Press, 2006; p. 120). É curioso perceber que, ao mesmo tempo em que empresas passam a atuar como intermediários entre os polos interessados, esse desenho não está isento de críticas, geralmente pautadas na afirmação de que essa dinâmica representaria nada mais do que a ascensão de novos intermediários, sendo mais correto reservar o nome "economia do compartilhamento" para práticas em que o compartilhamento fosse realizado diretamente entre os interessados.
} 
Sobre a questão da descentralização vale ainda ressaltar a possibilidade crescente de indivíduos fabricarem os itens de sua necessidade com o avanço das tecnologias de impressão 3D. O empoderamento que retira o consumidor de um estado de passividade (de consumidor para prossumidor), garantindo ao mesmo os meios para produzir itens que anteriormente seriam adquiridos no mercado, é fundamental para a compreensão da economia do compartilhamento. Essa lógica própria, e típica do desenvolvimento tecnológico, é resultado direto da expansão da World Wide Web como um espaço aberto para a inovação e hoje atinge não apenas a dinâmica do comércio, como também desafia o futuro do cenário industrial. ${ }^{5}$

O exemplo das impressoras 3D leva à segunda característica desse movimento: a redução dos custos de transação. $\mathrm{O}$ custo para se reproduzir desde uma obra intelectual até uma peça física é cada vez mais próximo de zero. Nesse sentido, a necessidade de empresas para galvanizar recursos e lidar com os custos de transação recebe a insólita companhia de pequenas iniciativas (por vezes até mesmo individuais).

O mercado da música talvez tenha sido um dos primeiros a sentir os efeitos dessa transformação quando músicos amadores a partir de suas casas começaram a atingir milhões através de plataformas online. Mas o achatamento dos custos de transação não se limitou à produção cultural, saltando rapidamente da economia criativa para um universo mais amplo de atividades, tornadas possíveis justamente pelo emprego intensivo de tecnologia.

Por fim, uma economia da atração, que entende as vontades pessoais e passa a tratar o indivíduo não como aquele para quem é empurrada uma demanda (push economy), mas sim como aquele que vê a sua demanda atendida (pull economy), se consolida. Para tanto, a confiança que emerge das relações pessoais é fundamental para a afirmação do momento de reflexão sobre as formas de atividade econômica.

O acesso gerado aos bens e aos serviços na economia do compartilhamento cria as condições para o desenvolvimento de um fenômeno denominado "consumo colaborativo", que privilegia justamente o acesso em detrimento da aquisição de propriedade sobre os bens que não serão explorados em todo o seu potencial. Dessa forma, o ato de se valer de bens, da expertise e até mesmo da disponibilidade alheia, sempre em constante mediação através da tecnologia, marca esse período. Compartilha-se o carro, o quarto, a casa, um saber prático ou mesmo o tempo vago.

Saberia então o homem verdadeiramente compartilhar? A narrativa sempre lembrada da tragédia dos comuns, conforme imaginada por Garrett Hardin, em 1968, parece indicar que, ao

\footnotetext{
${ }^{5}$ Vide ANDERSON, Chris. Makers: the new industrial revolution. Nova lorque: Crown, 2012; p. 225.
} 
agir apenas de acordo com os seus interesses particulares, o indivíduo terminaria por aniquilar ou reduzir os bens coletivos que garantem a qualidade de vida de todos. ${ }^{6}$

Buscando contrapor a conhecida figura, Yochai Benkler defende que a tecnologia poderia reduzir os impactos da tragédia dos comuns ao permitir a emergência de uma produção colaborativa entre pares. $\mathrm{O}$ autor procura evidenciar que existiria espaço para uma nova forma de produção e, consequentemente, de colaboração e compartilhamento entre os indivíduos, promovendo o bem-estar coletivo e o acesso individual a bens e a serviços. ${ }^{7}$

Uma consequência do cenário acima, no qual a aquisição de bens e a contratação de serviços de forma permanente dá lugar ao seu uso e prestação apenas quando necessário, termina por gerar não apenas uma nova lógica de apropriação de bens, mas também implica em uma significativa mudança para quem disponibiliza o bem ou o serviço, já que se procura retirar do mesmo o seu maior aproveitamento, evitando ociosidade e conectando a chamada economia do compartilhamento com uma cultura de colaboração e interatividade que marcou de modo muito relevante o desenvolvimento tecnológico das últimas décadas.

Diversas empresas, grandes ou pequenas, surgem na esteira do referido movimento. Seja através do aluguel de quartos de uma residência particular para curtas temporadas, do oferecimento para se cuidar de um animal de estimação alheio enquanto o dono viaja, da entrega de encomendas até inovadoras formas de se deslocar pela cidade, a economia do compartilhamento faz com que o possuidor de um bem que pode ser utilizado por terceiro possa alcançar um público interessado em se valer dele sem que a pessoa precise necessariamente adquirir o bem visado.

6 http://www.garretthardinsociety.org/articles/art_tragedy_of_the_commons.html (acessado em 05.06.2016).

${ }^{7}$ Ao enfatizar a relação entre a lógica do compartilhamento e tecnologia, assim se posiciona o autor: "To say that sharing is technology dependent is not to deny that it is a ubiquitous human phenomenon. Sharing is so deeply engrained in so many of our cultures that it would be difficult to argue that with the "right" (or perhaps "wrong") technological contingencies, it would simply disappear. My claim, however, is narrower. It is that the relative economic role of sharing changes with technology. There are technological conditions that require more or less capital, in larger or smaller packets, for effective provisioning of goods, services, and resources the people value. As these conditions change, the relative scope for social-sharing practices to play a role in production changes. When goods, services, and resources are widely dispersed, their owners can choose to engage with each other through social sharing instead of through markets or a formal, state-based relationship, because individuals have available to them the resources necessary to engage in such behavior without recourse to capital markets or the taxation power of the state." (BENKLER, Yochai. The Wealth of the Networks: how social production transforms markets and freedom. New Haven: Yale University Press, 2006; p. 120). 


\section{Compartilhamento e tecnologia}

A noção de compartilhamento, como dito, não é necessariamente nova no que diz respeito ao desenvolvimento tecnológico e o mesmo vale para a sua correlata conformação jurídica.

Nas últimas décadas, iniciativas como o desenvolvimento de software livre têm liderado o discurso sobre a lógica do compartilhamento aplicada à tecnologia da informação. Tendo como oposto o programa de computador desenvolvido de modo "proprietário", em que apenas se concede ao usuário uma licença restrita para utilizar o software, não sendo permitido estudar a sua programação, alterá-la e com isso criar novos programas, o software livre representa um movimento que, ao invés de ser alheio às práticas de mercado, terminou por angariar notória aceitação comercial com grandes empresas como a Sun Microsystems e a IBM, além de organizações mundialmente conhecidas como a Mozilla, desenvolvendo programas através de modelo aberto de licenciamento.

As denominadas quatro liberdades essenciais para que um software seja considerado livre são: (i) liberdade de executar o programa como desejado; (ii) liberdade de estudar o seu funcionamento e promover adaptações (sendo o acesso ao código-fonte um requisito para tanto); (iii) liberdade de redistribuir cópias do programa; e (iv) liberdade de distribuir as versões modificadas, dando assim oportunidade que toda a comunidade possa se valer das transformações realizadas. Essas liberdades estão no cerne de todo licenciamento envolvendo software livres, o que demonstra o paralelo entre desenvolvimento tecnológico e o consequente aperfeiçoamento jurídico que suporta esse ambiente colaborativo. ${ }^{8}$

Na feliz expressão de Tercio Sampaio Ferraz e Juliano Maranhão: "a licença livre não significa perda de direito subjetivo que passaria a ser comum, sob o não impedimento e a autonomia de todos. A leitura nesses termos clássicos não é adequada. A licença livre significa exercício autônomo da liberdade no sentido de reciprocidade no acesso à informação e ao conhecimento informático. Nesse processo, o não impedimento ao uso é conferido, pelo autor, a todos, mas a ninguém é conferida competência para alterar o regime. Pelo contrário, todos são obrigados a manter o regime livre definido pelo autor, mesmo sobre as derivações que vierem a produzir, preservando o autor o poder de disposição sobre as próprias derivações. Portanto, a

\footnotetext{
${ }^{8}$ Como destacam Sergio Branco e Walter Britto: "A partir da leitura do texto indicado, é fácil perceber que as questões envolvendo software livre não se centram em peculiaridades técnicas relacionadas ao software, mas sim peculiaridades jurídicas. Há que ficar claro que um software livre não se distingue dos demais em virtude de mecanismos técnicos." (In O que é Creative Commons? Rio de Janeiro: Editora FGV, 2013; p. 56).
} 
obra, mesmo em regime livre, continua sobre a esfera de atuação do autor, como forma de exercício de seu título, não importando abdicação ou transferência desse" ${ }^{9}$

Ao redor do software livre se formou uma comunidade de programadores e entusiastas que enxergam nessa forma de colaboração o meio mais eficaz para se criar programas cada vez mais sofisticados, seguros e que possam ser utilizados por um número crescente de pessoas. ${ }^{10}$

As lições aprendidas a partir da experiência do software livre geram impactos em outros setores criativos, com destaque para o desenvolvimento, especialmente na Internet, de um sistema de licenciamento jurídico que permitisse que músicas, textos, vídeos e também programas de computador, fossem amplamente difundidos, garantindo não apenas a autoria de seu criador, mas também já diretamente comunicando ao seu público quais liberdades seriam asseguradas com relação àquela obra.

Em outros termos, procura essa forma de licenciamento esclarecer se o usuário pode copiar a obra original, transformá-la, criando até mesmo uma nova obra e etc. Essas licenças, cuja iniciativa mais conhecida se denomina Creative Commons, adicionaram na década passada mais um componente sobre a cultura de compartilhamento e colaboração até então existente no desenvolvimento tecnológico. ${ }^{11}$

Para além dos códigos de programação, licenças como a Creative Commons expandiram o espectro do compartilhamento, sem que isso implicasse em qualquer contrariedade à possibilidade de que uma obra autoral, licenciada através de seus termos, pudesse gerar remuneração ao seu autor. Bastaria ao mesmo licenciar a obra apenas para fins não-comerciais, resguardando para si a contratação de qualquer uso comercial de sua criação.

A história da tecnologia da informação é marcada por movimentos cíclicos de abertura e fechamento, sempre instrumentalizados pelo consequente ferramental jurídico, conforme aponta Tim Wu. ${ }^{12}$ No caso da economia do compartilhamento, encontra-se diante de um fenômeno que

\footnotetext{
9 FERRAZ JUNIOR, Tercio Sampaio; MARANHÃO, Juliano. "Software Livre: A Administração Pública e a Comunhão do Conhecimento Informático", in FALCÃO, Joaquim; LEMOS, Ronaldo; e FERRAZ JUNIOR, Tercio Sampaio. Direito do Software Livre e a Administração Pública. Rio de Janeiro: Lumen Juris, 2007; p. 142.

${ }^{10} \mathrm{O}$ exemplo do software livre como comunidade baseada no compartilhamento é também explorado por Stefano Rodotà em seu La Vita e le Regole: tra diritto e non diritto. Milão: Feltrinelli, 2007; p. 134.

11 "Por meio desses documentos, o titular dos direitos autorais informa, previamente e expressamente, que usos permite que sejam dados à sua obra. Assim, aquele que tem acesso à obra sabe exatamente em que limite poderá dela se valer. Esses limites incluem as possibilidades de reproduzir, de modificar ou de explorar a obra economicamente - segundo convencionado pelo titular dos direitos autorais. " (BRANCO, Sergio; BRITTO, Walter. O que é Creative Commons? Rio de Janeiro: Editora FGV, 2013; p. 29)

${ }^{12}$ Segundo o autor: "A história mostra uma progressão característica das tecnologias da informação: de um simples passatempo à formação de uma indústria; de engenhocas improvisadas a produtos maravilhosos; de
} 
alia o potencial de colaboração nutrido nas últimas décadas por movimentos como o software livre e o Creative Commons com a oportunidade de se desenvolver modelos de negócio que ampliam o uso de bens e o acesso a serviços. ${ }^{13}$

Todavia, é importante perceber que debaixo do conceito abrangente de economia do compartilhamento as mais variadas espécies de atividades são desempenhadas, desde aquelas que repudiam frontalmente a figura da empresa e com isso apontam para uma superação da lógica capitalista corrente, até aquelas que se ancoram na existência de uma empresa que desenvolve a tecnologia e viabiliza o contato entre os polos interessados.

Se é verdade que colaboração e tecnologia andam lado a lado, é justamente no componente jurídico que se pode encontrar uma das peças fundamentais para desvendar o futuro do movimento. Por isso, a seguir são abordadas algumas questões jurídicas que podem ser identificadas como fundamentais para a compreensão das transformações proporcionadas pela economia do compartilhamento.

\section{Alguns aspectos jurídicos da economia do compartilhamento}

Muito pode ser dito sobre os impactos jurídicos da economia do compartilhamento, sobretudo quando se alia à análise o desenvolvimento tecnológico através de plataformas online e aplicativos. Questionamentos sobre propriedade, contrato, responsabilidade e trabalho surgem de imediato.

canal de acesso livre a meio controlado por um só cartel ou corporação - do sistema aberto para o fechado. Trata-se de uma progressão comum e inevitável, embora essa tendência mal estivesse sugerida na alvorada de qualquer das tecnologias transformadoras do século passado, fosse ela telefonia, rádio, televisão ou cinema. A história mostra também que qualquer sistema fechado por um longo período se torna maduro para um surto de criatividade: com o tempo, uma indústria fechada pode se abrir e se renovar, fazendo com que novas possibilidades técnicas e formas de expressão se integrem ao meio antes que o empenho para fechar o sistema também comece a atuar. " (WU, Tim. Impérios da Comunicação: do telefone à internet, da AT\&T ao Google. Rio de Janeiro: Zahar, 2012; p. 13.)

${ }^{13}$ Sobre o futuro da economia do compartilhamento, explica Ricardo Abramovay: "Não há qualquer garantia que os potenciais embutidos na oferta descentralizada, nos menores custos de transação e na emergência de uma economia da atração superem os principais impasses e desafios da economia tipicamente industrial. O conteúdo da economia híbrida do século XXI não está dado de antemão pelo poder da ciência e da técnica: ele depende fundamentalmente da capacidade que um leque variado de movimentos sociais terá para fazer com que as valorizações dos bens comuns tenham prioridade com relação aos interesses privados, na maneira como a rede se constrói. Um mundo em que a conexão em rede abra caminho a mudanças reais no sentido de democratizar a organização e o exercício do poder econômico, político e cultural não emerge espontaneamente do processo evolutivo da ciência e das técnicas. " (ABRAMOVAY, Ricardo. "A Economia Híbrida do Século XXI", in COSTA, Eliane; AGUSTINI, Gabriela (orgs) De Baixo para Cima. Rio de Janeiro: Aeroplano, 2014; pp. 128). 
Para os fins deste curto artigo, cumpre então focar em dois elementos centrais para o entendimento das iniciativas características da economia do compartilhamento. De um lado, é preciso perceber como esse fenômeno promove o uso eficiente dos bens e, consequentemente, atende às demandas relativas à sua função social, conforme reconhecidas pela legislação.

Adicionalmente, o uso da tecnologia da informação aperfeiçoa a prática da transparência nas relações contratuais, promovendo um fortalecimento dos ditames da boa-fé objetiva. A tutela da confiança é assim aprimorada lado a lado com o desenvolvimento de novos mecanismos que permitem às partes pactuarem de modo claro e informado.

\section{Uso eficiente e função social dos bens}

Uma das mais evidentes características da economia do compartilhamento é a ampliação do uso eficiente dos bens e o consequente atendimento de sua função social. Embora a doutrina geralmente se dedique mais ao estudo da função social da propriedade imóvel do que àquela pertinente aos bens móveis, vale aqui trazer as referências que, ainda que pensadas para os imóveis, são de todo aplicáveis à lógica da economia do compartilhamento ${ }^{14}$ e ao acesso gerado a bens, como automóveis disponibilizados através de aplicativos que permitem contratar o transporte privado pela cidade.

Todo direito, assim como o direito à propriedade, pode ser visto pelo prisma de sua estrutura ou de sua função. Na dicção sempre repetida de Pietro Perlingieri, “o 'como é?' evidencia a estrutura, 'para que serve?' evidencia a função" ${ }^{15}$.

O conteúdo estrutural do direito de propriedade é composto pelas faculdades de usar, gozar e dispor da coisa, sendo ainda facultado ao titular mover as competentes ações relativas ao domínio para assegurar a tutela do seu direito. Esse conjunto de elementos compõe a estrutura, mas não retratam ainda a função do direito de propriedade. ${ }^{16} \mathrm{O}$ perfil estrutural do direito de

\footnotetext{
${ }^{14}$ Nessa direção, e alertando para que a natureza jurídica do bem importa menos do que os usos que são feitos dele, vale destacar o comentário de Roberta Mauro: "Em outras palavras, a função social faz com que importe menos a natureza do bem ou a sua classificação em abstrato, já que a sua disciplina jurídica e a tutela que Ihe é conferida irão variar não com base em tais características, mas sim em virtude do papel por ele desempenhado ou dos usos que dele se faz na relação jurídica oncreta. " (MAURO, Roberta. "A propriedade na Constituição de 1988 e o problema do acesso aos bens", in TEPEDINO, Gustavo; FACHIN, Luis Edson (orgs.) Diálogos sobre Direito Civil, volume II. Rio de Janeiro: Renovar, 2008; p. 39.

${ }^{15}$ PERLINGIERI, Pietro. Perfis do Direito Civil: Introdução ao Direito Civil Constitucional. Rio de Janeiro: Renovar, 1997; p. 94.

${ }^{16}$ TEPEDINO, Gustavo. "Contornos constitucionais da propriedade privada", in Temas de Direito Civil, vol. I. Rio de Janeiro: Renovar, 2003; p. 269.
} 
propriedade encontra o seu núcleo central no exercício de um poder pelo seu titular, gerando a sujeição de terceiros a esse assenhoramento do titular sobre a coisa. ${ }^{17}$

A função social vem então a se agregar ao elemento estrutural do direito, trazendo consigo a análise sobre as finalidades e os valores que devem ser alcançados através do desempenho do domínio sobre os bens. Sem cair na armadilha de estipular um alvo fixo a ser buscado pelo direito, é preciso compreender que não existe uma função da propriedade, mas sim funções que podem variar de acordo com o tipo de estatuto, com o tipo de propriedade sobre o qual se discute.

De toda forma, pode-se afirmar que a doutrina contemporânea reconhece na função social da propriedade um elemento que viabiliza a concretização de valores e termina por qualificar a própria extensão do poder que o titular exerce sobre o bem. Como recorda o Ministro Luis Edson Fachin, impor uma função - no caso social - importa em determinar uma direção. ${ }^{18}$ Seria então a função social da propriedade dotada da capacidade de alterar a estrutura do domínio, inserindo-se em seu perfil interno e atuando como critério de valoração do exercício do direito. ${ }^{19}$

É equivocado imaginar a função social da propriedade como um limitador externo ao livre exercício dos poderes inerentes ao domínio por parte do titular. $\mathrm{O}$ antagonismo entre função social e liberdades amplas do titular mascara uma concepção ultrapassada que enxerga o direito de propriedade como um elemento monolítico, composto apenas de poderes e liberdades, sendo qualquer restrição ao exercício desses poderes um fator exógeno ao exercício do direito em si. Com esse raciocínio, o direito de propriedade se fecha no círculo vicioso dos egoísmos privados. Muito ao contrário, é importante perceber como a função social integra a essência do direito de propriedade, uma vez que os elementos estruturais e funcionais compõem o direito em si. ${ }^{20}$

A Constituição Federal, ao dispor sobre o direito de propriedade, insere a sua disciplina no rol dos direitos fundamentais, sendo a sua tutela constante do art. 5ํ, XXII. Logo no inciso seguinte, determina que "a propriedade atenderá a sua função social". Da mesma forma, a propriedade

\footnotetext{
${ }^{17}$ Conforme explicita, Francisco Santoro-Passarelli: "Assim na propriedade como nos outros direitos reais, que se constituem na senhoria independente e imediata do titular sobre a coisa, o conteúdo prevalecente do direito subjetivo é o próprio poder, para o qual é instrumental a pretensão do titular contra outros sujeitos. ", in Dottrine Generali del Diritto Civile. Nápoles: Jovene, ga ed., 2002; p. 71 (trad. livre).

${ }^{18}$ FACHIN, Luis Edson. Teoria Crítica do Direito Civil. Rio de Janeiro: Renovar, 2000; p. 209.

${ }^{19}$ TEPEDINO, Gustavo. "Contornos constitucionais da propriedade privada", in Temas de Direito Civil, vol. I. Rio de Janeiro: Renovar, 2003; p. 282.

${ }^{20}$ Assim como os interesses econômicos e sociais sobre o bem também se integram, se não mais por nada porque a ineficiência econômica causa escassez de recursos, o que, em última instância, causa um empobrecimento à coletividade. Nesse sentido, vide TRIMARCHI, Pietro. Istituzioni di Diritto Privato. Milão: Giuffrè, 2007; p. 459.
} 
privada e a sua função social são também reconhecidas constitucionalmente como princípios da Ordem Econômica (art. 170, II e III).

Para além do debate sobre a função social da propriedade urbana e rural, que transcendem o escopo deste artigo, vale notar que o racional por trás de se funcionalizar a propriedade aparece nos dispositivos constitucionais, especialmente quando, ao tratar da propriedade rural, a CFRB determina em seu artigo 186 que a função social é cumprida quando a propriedade rural atende, simultaneamente, segundo critérios e graus de exigência estabelecidos em lei, a requisitos como o aproveitamento racional e adequado e a utilização adequada dos recursos naturais disponíveis e preservação do meio ambiente.

No que tange à propriedade urbana, na legislação infraconstitucional pode-se mencionar a redação do art. 39 do chamado Estatuto da Cidade (Lei no 10.257/2001), que assim dispõe sobre a função social da propriedade urbana, de forma complementar à diretriz constitucional: “Art. 39. A propriedade urbana cumpre sua função social quando atende às exigências fundamentais de ordenação da cidade expressas no plano diretor, assegurando o atendimento das necessidades dos cidadãos quanto à qualidade de vida, à justiça social e ao desenvolvimento das atividades econômicas, respeitadas as diretrizes previstas no art. $2^{\circ}$ desta Lei." (grifamos)

Da conjugação dos dispositivos acima se percebe como o ordenamento jurídico brasileiro, ao tratar da propriedade dos bens imóveis, elencou em diversos momentos como critério para o seu atendimento: (i) o aproveitamento racional e adequado; (ii) preocupações com a sustentabilidade; (iii) o atendimento à necessidade relativas à qualidade de vida das pessoas; e (iv) o desenvolvimento de atividades econômicas através do bem.

Esses quadrantes, aplicáveis tanto aos bens imóveis como aos bens móveis, permitem perceber como iniciativas típicas da economia do compartilhamento atingem as demandas correspondentes à função social dos bens.

Tome-se por exemplo os aplicativos que permitem que pessoas possam contratar o transporte privado pela cidade, unindo passageiros e motoristas interessados, conforme realizado, por exemplo, pela Uber. No que diz respeito ao aproveitamento racional e adequado, é fácil perceber que deixar um carro, que poderia ser usado, parado na garagem não pode ser a forma mais eficiente de aproveitar integralmente a utilidade do bem. Ao permitir que motoristas 
profissionais possam conduzir passageiros interessados através de corridas solicitadas pelo aplicativo, é potencializado o uso dos automóveis cadastrados nas plataformas online. ${ }^{21}$

Já com relação às preocupações concernentes ao meio ambiente e à sustentabilidade, o recurso a aplicativos que permitem contatar transporte privado auxilia a diminuir o número de carros com apenas o motorista circulando na cidade, já que uma parcela de seus clientes são justamente aqueles que deixam de utilizar um carro próprio para se valer do transporte solicitado através do aplicativo. Poder-se-ia imaginar que, ao aumentar a frota de carros que podem servir para o transporte de passageiros individuais, sejam aqueles que prestam serviço de taxis, sejam aqueles que atuam de modo a oferecer transporte privado e individual, como a Uber e os motoristas executivos, existiria aqui um prejuízo ao meio-ambiente já saturado dos grandes centros urbanos. Essa é uma questão que ainda carece de maiores estudos, mas aparentemente o oferecimento de mais alternativas para que o proprietário de um automóvel venha a utilizar um carro alheio para ser transportado parece contribuir para que um número menor de carros ociosos circulem pela cidade, otimizando o transporte e reduzindo o impacto ambiental.

Ao oferecer a contratação de transporte em modalidade que, conforme abaixo descrito, garante conforto, transparência e confiança ao passageiro, é assegurado ao mesmo um incremento em sua qualidade de vida. ${ }^{22}$

Por fim, a compatibilidade entre o discurso sobre a função social dos bens e os aplicativos de transporte no ambiente de desenvolvimento de atividades econômicas é também uma particularidade que chama atenção, justamente porque todo o discurso sobre função social da propriedade (seja dos bens imóveis, como dos bens móveis) está geralmente ligado à tentativa de se limitar o uso daquele proprietário que abusa do seu direito sobre a coisa, valendo-se dela sem que o bem seja explorado em benefício da coletividade. No caso presente, têm-se justamente o contrário, já que através dos aplicativos se torna possível ao proprietário de um bem (no caso um automóvel) explorar o mesmo de modo a atender a sua função social.

\footnotetext{
${ }^{21}$ Não é raro encontrar um motorista, quando o mesmo atende à demanda pelo aplicativo, que relata ser a sua principal ocupação servir de transporte executivo para empresas ou para clientes particulares. Quando não existe demanda por esses clientes já estabelecidos, o motorista liga o aplicativo e passa a operar como um motorista através do app, o que lhe garante não apenas uma remuneração extra, como também atende à necessidade de um novo cliente e maximiza o aproveitamento eficiente do automóvel.

22 Essa particularidade intrínseca ao atendimento da função social dos bens chama a atenção justamente pela diversidade de situações em que o recurso ao aplicativo pode ser manejado pelos mais diferentes públicos, seja pais preocupados com a segurança de seus filhos em transportes individuais ou a contratação de transporte para a ida a uma festa ou cerimônia na qual o cliente busca mais conforto e, em caso de consumo de bebidas alcoólicas, evitar qualquer infração às leis de trânsito.
} 
Essa é justamente a concepção contemporânea da função social da propriedade que, conforme destacado por Pietro Perlingieri, não se reduz à noção de limitação do atuar do proprietário, mas que, ao reverso, busca desenvolver um tino promocional, prestigiando as formas de utilização da propriedade que reforçam os princípios de solidariedade econômica, política, social e o pleno desenvolvimento da personalidade. Assim, é retirado da expressão função social da propriedade qualquer sinal de ódio à propriedade privada e se afirma em sua aplicação o vetor para que, através do exercício da propriedade, sejam alcançados os fins previstos no texto constitucional. ${ }^{23}$

Dessa forma, vale ressaltar que não existe qualquer incompatibilidade entre o exercício da função social e a exploração econômica do bem dentro do sistema econômico capitalista. Muito ao reverso, conforme ressalta Anderson Schreiber, é importante esclarecer que "funcionalizar a propriedade ao atendimento de interesses sociais não significa, de modo algum, propor o aniquilamento dos direitos individuais ou pregar a negação da propriedade privada. Muito pelo contrário. A função social, impondo ao proprietário a observância de determinados valores sociais, legitima a propriedade capitalista e a compatibiliza com a democracia social que caracteriza os sistemas políticos contemporâneos." 24

\section{Transparência gerada por sistema de avaliação}

Uma segunda característica da economia do compartilhamento que gera amplos efeitos jurídicos é a transparência produzida pelas plataformas online aqui mencionadas. No caso de aplicativos para contratação de transporte, ao chamar um motorista identificado através do app, o passageiro desde já conhece o nome de quem prestará a atividade, além de visualizar uma foto do motorista, o tipo de carro e, de forma mais importante, a sua avaliação. O mesmo vale para uma série de outras plataformas, como a Airbnb, que permite ao interessado em um apartamento

\footnotetext{
${ }^{23}$ PERLINGIERI, Pietro. II Diritto Civile nella Legalità Costituzionale. Nápoles: Edizioni Scientifiche Italiane, 2001; p. 445.

${ }^{24}$ SCHREIBER, Anderson. Direito Civil Constitucional. São Paulo: Atlas, 2014; p. 247. Ainda sobre a vinculação entre liberdade para o exercício de suas atividades e a correspondente vinculação social, afirma Léon Duguit: "A liberdade, sem dúvida, é um direito e não uma prerrogativa que acompanha um homem pela sua natureza de homem. A liberdade é um direito porque o homem tem o dever de desenvolver sua atividade tão plenamente quanto possível, uma vez que a sua atividade individual é fator essencial da solidariedade por divisão de trabalho. Enfim, o homem desfruta o direito de desenvolver sua atividade com liberdade, mas, ao mesmo tempo, só possui esse direito enquanto consagra seu exercício a realização da solidariedade social. A liberdade concebida dessa forma assume um caráter inabalável, pois nesse sentido consiste unicamente na liberdade de se cumprir o dever social. " (Fundamentos do Direito. São Paulo: Ícone, 1996; p. 28)
} 
conhecer não apenas as suas condições, mas também o histórico de ocupação e avaliações passadas sobre o bem e seu proprietário.

A disponibilização dessas informações é um instrumento fundamental para a criação de um ambiente que incentive a formação de confiança entre aquele que busca um produto ou o desenvolvimento de uma atividade e quem pode atender à demanda. Por ser pautada por relações cada vez mais pessoais, ainda que prestadas por ou através de empresas, a economia do compartilhamento depende desse incremento no nível de transparência para que os indivíduos possam saber quem prestará a atividade solicitada e, até mesmo com base nas informações que venham a ser disponibilizadas, possam decidir sobre a efetiva contratação ou não.

Assim sendo, como um primeiro passo no sentido de radicalizar o atendimento do dever de informação, primado derivado do princípio jurídico da boa-fé objetiva, cabe às empresas que desenvolvem atividades típicas da economia do compartilhamento oferecer o maior número de informações que possam levar ao comportamento concluinte do contrato.

Essa postura, apoiada em inovadoras plataformas tecnológicas, pode não apenas humanizar a relação de natureza patrimonial que se busca desenvolver, como também fornecer os elementos necessários para a formação da vontade do usuário da plataforma. Quanto mais informações forem passadas, e maior a sua relevância para a conclusão do contrato e a melhoria da experiência de uso da plataforma, mais atendido certamente será o princípio da boa-fé objetiva, conforme disposto no artigo 422 do Código Civil.

\section{Reputação e tutela da confiança}

O conhecimento de informações sobre quem prestará a atividade ou providenciará o acesso a determinado bem é, como dito, o primeiro passo no cumprimento integral do dever de informar e, em última instância, do princípio da boa-fé objetiva. Um fator adicional reside então no efeito que a transparência gera sobre os usuários da plataforma. Aqui cuida-se de explorar o papel crescente dedicado à reputação e à tutela da confiança. ${ }^{25}$

\footnotetext{
${ }^{25}$ Se o contrato em si já é um instrumento que visa à eliminação de riscos e desconfianças entre as pessoas que o celebram, a tutela da confiança representa um passo adicional para que, mesmo em meio ao que muitos chamam de crise do contrato, possa ser encontrado nas relações travadas pela Internet, com toda as suas peculiaridades, um ambiente profícuo para que a confiança seja incrementada. Sobre as peculiaridades da contratação através da Internet, afirma Claudia Lima Marques que "o uso de um meio virtual ou a entrada em uma cultura visual leva a uma perda de significado ou de eficiência do princípio da boa-fé, que guiou o direito privado e, em especial o consumidor no século XX. Para alcançar a mesma eficácia em tempos virtuais pós-modernos, pareceu-me necessário evoluir para o uso de um paradigma mais visual (de aparência), de
} 
A avaliação do motorista dá ao passageiro uma noção do histórico de corridas efetuadas pelo condutor e como os passageiros anteriores apreciaram (ou não) a atividade prestada. histórico de críticas ou elogios ao proprietário de um apartamento e ao imóvel em si permitem que o interessado possa decidir de modo cada vez mais informado.

Essa relevância destacada dos mecanismos de avaliação, presente em diversas atividades desenvolvidas na Internet, empodera o usuário, que passa a contar com uma ferramenta construída colaborativamente para obter informações que sozinho jamais conseguiria. A transparência gerada pelo aplicativo cria assim não apenas um ambiente no qual a reputação é o ativo mais importante para quem disponibiliza um bem ou presta uma atividade, ao mesmo tempo em que gera o efeito de estimular a confiança no sentido de que a atividade será bem desempenhada, reduzindo riscos e aumentando o cuidado com a outra parte contratante. ${ }^{26}$

A construção da reputação em sites e aplicativos que permitem a sua avaliação e acompanhamento é um dos mais instigantes temas da economia do compartilhamento. Pode-se afirmar que o sucesso de um motorista do Uber, de uma pessoa que aluga seus quartos no Airbnb ou mesmo do vendedor de seus bens no Mercado Livre é determinado pela sua reputação. E aqui a reputação atua em dois canais.

menos fidelidade e personalização (fides), de menos eticidade (valoração - bona) e sim de mais socialidade (qualquer forma de declaração vincula o profissional organizador da cadeia de fornecimento) e de coletiva repersonalização (realizar as expectativas legítimas de todo um grupo difuso de consumidores virtuais), a confiança, o modelo-mãe da boa-fé! Esta tese pode ser defendida em matéria de contratos civis, comerciais e de consumo, hoje, após a entrada em vigor do Código Civil de 2002 e suas noções basilares de função social dos contratos, boa-fé objetiva, bons costumes e combate ao abuso nos contratos paritários. Parece-me, pois, que o direito privado do século XXI como um todo deve evoluir para redescobrir o princípio da confiança (Vertrauensprinzip)! " ("A chamada nova crise do contrato e o modelo de direito privado brasileiro: crise de confiança ou de crescimento do contrato?", in MARQUES, Claudia Lima (coord) A Nova Crise do Contrato: Estudos sobre a nova teoria contratual. São Paulo: Revista dos Tribunais, 2007; p. 21). Especificamente sobre o princípio da confiança em contratos de consumo, vinculando o seu desenvolvimento ao princípio da transparência, vide FILHO, Sergio Cavalieri. Programa de Direito do Consumidor. São Paulo: Atlas, 2008; p. 36.

${ }^{26}$ Em um mercado, que define como contendo as características de "maximização dos proveitos e da rentabilidade dos investimentos, despersonalização e objetivação na conduta, segurança qualificada das transações", afirma Carneiro da Frada que "a doutrina dos deveres de proteção acaba realmente por corresponder a uma necessidade funcional do tráfico negocial, potenciando padrões acrescidos de segurança e zonas desoneradas de risco nesse setor". (CARNEIRO DA FRADA, Manuel A. Contrato e Deveres de Proteção. Separata do Volume XXXVIII do Suplemento ao Boletim da Faculdade de Direito da Universidade de Coimbra, 1994; p. 278). Um efeito adicional do papel desempenhado pela confiança nas relações mediadas pelas modernas tecnologias da informação é justamente a simplificação de sistemas complexos cuja compreensão jamais poderia ser exigida da parte contratante. Nesse sentido, vide MARTINS, Guilherme Magalhães. Responsabilidade Civil por Acidente de Consumo na Internet. São Paulo: Revista dos Tribunais, 2008; p. 88. 
Por um lado, ao construir um sistema ancorado na reputação (quanto melhor avaliação, maior a sua reputação na plataforma), o sistema incentiva uma melhor prestação da atividade tendo em vista que a avaliação concedida pelo usuário será visível para futuros clientes. Por outro, ao exibir a avaliação de usuários anteriores, a plataforma induz o aumento de confiança, não apenas no que diz respeito a quem prestará a atividade, mas com relação à plataforma como um todo. Quanto mais uma boa avaliação corresponder à prestação satisfatória da atividade, mais confiável se torna a plataforma.

Existe ainda um efeito nada desprezível no que diz respeito à tutela da confiança na economia do compartilhamento. Trata-se do aumento do nível de confiança não apenas na realização da atividade ou com relação à plataforma, mas sim entre as pessoas como um todo. Ao permitir que alguém que até então era um estranho ingresse no seu carro (ou alternativamente ao ingressar no carro de um estranho), a plataforma cria bases para que as pessoas possam confiar mais umas nas outras. ${ }^{27}$

O mesmo raciocínio pode ser aplicado para outras aplicações típicas da economia do compartilhamento, como o aluguel de quartos ou de residências para curtas estadias. É certo que um eficiente regime de seguros deve existir para indenizar eventuais danos decorrentes do uso do bem ou da realização da atividade, mas esse mecanismo jurídico em nada enfraquece o componente de confiança que parece estar no cerne do desenvolvimento da economia do compartilhamento.

Por fim, como forma de mitigar os imprevistos da desconfiança, aplicações típicas da economia do compartilhamento, como verdadeiros mercados de duas pontas, permitem não apenas a avaliação de quem garante acesso ao bem ou realiza a atividade, mas também de quem se vale da coisa ou da atividade contratada. Assim, quem contrata também é objeto de avaliação e cria com isso a sua própria reputação.

\footnotetext{
${ }^{27}$ Esse fator ganha ainda mais relevância quando se percebe, conforme destaca Teresa Negreiros, que a boafé objetiva prevista no Código Civil acaba exercendo o papel de forçar uma recondução da confiança para dentro de contratos cuja prática tem disseminado justo o sentimento oposto. Segundo lembra a autora: "Lamentavelmente, porém, o agir com boa-fé, hoje um comando normativo expressamente consagrado em um dos dispositivos de maior ressonância do Código Civil de 2002 (art. 422), revela-se cada menos frequente, tanto na esfera dos negócios exclusivamente privados, como no trato da coisa pública. A extraordinária simpatia alcançada nos últimos tempos pelo caráter potencialmente transformador do princípio da boa-fé aparece, por isso e antes de mais nada, como um índice da escassez de comportamentos e atitudes que, na prática contratual, expressem concretamente o ideal da boa-fé. " "O princípio da boa-fé contratual", in BODIN DE MORAES, Maria Celina (coord). Princípios do Direito Civil Contemporâneo. Rio de Janeiro: Renovar, 2006; p. 222).
} 
Nesse sentido, um detalhe que não deve passar desapercebido é o fato de que, quanto mais dependente se torna essa economia do conhecimento de avaliações e reputações alheias, mais parece estranho que a reputação até então fique adstrita aos confins do site ou da aplicação na qual a mesma foi realizada. Um dos próximos passos que começa a ser dado, é refletir sobre a reputação alcançada em determinada plataforma como uma característica que integra o patrimônio do usuário e, sendo assim poderia ser compartilhada entre diferentes plataformas.

Esse passo não apenas poderia evitar a compartimentalização de tão relevante informação, como também servir de base para uma nova plataforma quando o usuário procurasse ingressar na mesma. Os limites deste texto não permitem aqui alongar sobre os paralelos entre reputação na economia do compartilhamento e cadastros de restrição ao crédito, ou mesmo na eventual "portabilidade" da reputação e os impactos na tutela da privacidade e dos dados pessoais, mas servem essas considerações para evidenciar o seu papel em todas as empresas dedicadas à chamada economia do compartilhamento.

\section{IMPACTOS DA ECONOMIA DO COMPARTILHAMENTO NAS CIDADES}

A expansão de atividades usualmente classificadas como parte da economia do compartilhamento gera inegáveis impactos sobre as formas pelas quais as pessoas se movimentam, se hospedam e utilizam os variados serviços na cidade. É natural que a velocidade de adoção dessas atividades seja proporcional à resistência praticada por modelos de negócio desenvolvidos em diversos segmentos. O debate sobre a eventual necessidade de regulação de atividades relacionadas à economia do compartilhamento escapa aos contornos deste texto, mas é relevante, ainda que brevemente, apontar alguns impactos que as referidas atividades representam na dinâmica das cidades.

A adoção de aplicativos que viabilizam a contratação de transporte privado pode servir de exemplo ao promover uma inédita visão sobre os deslocamentos na cidade. Ao usar dados de geolocalização para monitorar os automóveis que prestam atividades de transporte a partir do aplicativo, as empresas que exploram essas atividades passam a deter não apenas uma base de dados de grande relevo sobre a movimentação de pessoas na cidade, como ainda pode influenciar a forma pela qual os passageiros se deslocam pela mesma.

Em tempos em que o chamado big data, ou seja, o tratamento de grande volume de dados tem revolucionado a forma pela qual se planeja o funcionamento das ditas cidades inteligentes, as empresas podem através do seu aplicativo não apenas se valer dessa base de dados para uma série 
de outras aplicações (desde que sempre preservando os dados pessoais dos envolvidos), como até oferecer ao cliente o motorista que sempre se encontrará mais próximo do seu local de partida, reduzindo o tempo de espera e aumentando o aproveitamento do veículo pela cidade.

Recentemente a expansão de aplicativos de carona e modalidades implementadas em aplicativos populares, como o Uber (através da modalidade Uber Pool ${ }^{28}$ ), impulsionam ainda mais uma melhor utilização dos veículos. Nesse sentido, não apenas é gerada a oportunidade de uma remuneração para o motorista ${ }^{29}$, como também é aumentado o aproveitamento do espaço ocioso em automóveis. Esse aproveitamento da ociosidade dos bens, como visto, é parte essencial de algumas das mais conhecidas atividades que constituem a chamada economia do compartilhamento.

No que diz respeito à atividade de hospedagem de pessoas em residências, conforme impulsionado por populares iniciativas típicas da economia do compartilhamento, o impacto sobre as cidades é evidente. Ao aumentar as possibilidades de hospedagem, os aplicativos não apenas oferecem uma experiência alternativa àquela proporcionada pela rede hoteleira, como também estimula que turistas e viajantes se hospedem em partes das cidades que nem sempre são vistas como áreas turísticas.

Essa diversificação na alocação de turistas pode transformar o modo pelo qual as cidades se planejam para receber visitantes ${ }^{30}$, ao mesmo tempo em que oferece para o viajante a possibilidade de experimentar uma cidade a partir do ponto de vista um pouco mais aproximado daquele que ali reside. Não é desprezível o potencial desse componente para transformar a forma pela qual as cidades se organizam para exibir seus potenciais turísticos e o modo pelo qual se viaja.

\footnotetext{
${ }^{28}$ Segundo informações da Uber, metade das corridas realizadas através do seu aplicativo na cidade de São Francisco são feitas na modalidade "Pool", sendo possível assim compartilhar o veículo com demais passageiros que desejam ir para uma direção aproximada. In: https://newsroom.uber.com/uscm/ (acessado em 21.09.2016).

${ }^{29}$ Segundo estudo de Hall e Krueger são três os grupos de motoristas que utilizam o aplicativo da Uber: (i) os que utilizam o aplicativo como a sua única atividade profissional representam 38\%; (ii) os que trabalham em tempo integral em um emprego e ainda ocupam o seu tempo livre com corridas contratadas através do aplicativo são 31\%; e (iii) aqueles que trabalham em meio-período e ainda complementam a sua renda com corridas através do app representam cerca de $30 \%$ da base de motoristas cadastrados (in HALL, Jonathan; KRUEGER, Allan. "An Analysis of the Labor Market for Uber's Driver-Partners in the United States", disponivel em: https://s3.amazonaws.com/uber-static/comms/PDF/Uber_Driver-Partners_Hall_Kreuger_2015.pdf, acessado em 21.09.2016).

30 De acordo com informações divulgadas pela Airbnb, a empresa gerou em um ano na cidade de Nova lorque cerca de USD 104.000.000 (cento e quatro milhões de dólares) em transações realizadas fora do perímetro turístico do distrito de Manhattan. In: http://blog.airbnb.com/airbnbs-economic-impact-nyccommunity/ (acessado em 21.09.2016).
} 


\section{CONCLUSÃO}

A tecnologia da informação vem impulsionando diversas transformações nas formas de acesso a bens e a serviços. Por mais que a chamada economia do compartilhamento atravesse embates conceituais, é importante compreender como a dinâmica do compartilhamento não apenas é reforçada pelo desenvolvimento tecnológico, como também se apoia em uma construção jurídica que busca esclarecer os fundamentos e os efeitos decorrentes de suas práticas.

A escolha da função social dos bens e da tutela da confiança visa a enfatizar como o fenômeno da economia do compartilhamento está inserido no arcabouço principiológico que anima a aplicação do ordenamento jurídico. Não se buscou aqui aprofundar a discussão sobre regimes de responsabilidade ou natureza do vínculo que une os diversos atores que participam das iniciativas típicas da economia do compartilhamento.

Todavia, procurou-se indicar caminhos que possam levar na direção de uma pesquisa mais aprofundada sobre o entrelaçamento dos elementos que são essenciais à economia do compartilhamento com algumas pedras de toque da principiologia constitucional e contratual. Elas auxiliam ainda na percepção do impacto que a funcionalização dos bens e a confiança nas relações podem desempenhar para a transformação das cidades.

A contribuição que a função social dos bens e a tutela da confiança desempenha na configuração das iniciativas da economia do compartilhamento não deve ser desprezada. Ela representa um caminho que pode afastar o entusiasmo e o deslumbramento que toda inovação tecnológica traz consigo, oferecendo direções que ao mesmo tempo justifiquem e permitam a melhor compreensão desse fenômeno.

\section{BIBLIOGRAFIA}

ABRAMOVAY, Ricardo. "A Economia Híbrida do Século XXI", in COSTA, Eliane; AGUSTINI, Gabriela (orgs) De Baixo para Cima. Rio de Janeiro: Aeroplano, 2014; pp. 104/131.

ANDERSON, Chris. Makers: the new industrial revolution. Nova lorque: Crown, 2012.

BENKLER, Yochai. The Wealth of the Networks: how social production transforms markets and freedom. New Haven: Yale University Press, 2006.

BRANCO, Sergio e BRITTO, Walter. O que é Creative Commons? Rio de Janeiro: Editora FGV, 2013.

CARNEIRO DA FRADA, Manuel A. Contrato e Deveres de Proteção. Separata do Volume XXXVIII do Suplemento ao Boletim da Faculdade de Direito da Universidade de Coimbra, 1994. 
DUGUIT, Léon. Fundamentos do Direito. São Paulo: Ícone, 1996.

FACHIN, Luis Edson. Teoria Crítica do Direito Civil. Rio de Janeiro: Renovar, 2000.

FERRAZ JUNIOR, Tercio Sampaio; MARANHÃO, Juliano. "Software Livre: A Administração Pública e a Comunhão do Conhecimento Informático", in FALCÃO, Joaquim; LEMOS, Ronaldo; e FERRAZ JUNIOR, Tercio Sampaio. Direito do Software Livre e a Administração Pública. Rio de Janeiro: Lumen Juris, 2007; p. 115/164.

FILHO, Sergio Cavalieri. Programa de Direito do Consumidor. São Paulo: Atlas, 2008.

HALL, Jonathan; KRUEGER, Allan. "An Analysis of the Labor Market for Uber's Driver-Partners in the United States", disponível em https://s3.amazonaws.com/uber-static/comms/PDF/Uber_DriverPartners_Hall_Kreuger_2015.pdf, acessado em 21.09.2016.

MARQUES, Claudia Lima (coord) A Nova Crise do Contrato: Estudos sobre a nova teoria contratual. São Paulo: Revista dos Tribunais, 2007.

MARTINS, Guilherme Magalhães. Responsabilidade Civil por Acidente de Consumo na Internet. São Paulo: Revista dos Tribunais, 2008.

MAURO, Roberta. "A propriedade na Constituição de 1988 e o problema do acesso aos bens", in TEPEDINO, Gustavo; FACHIN, Luis Edson (orgs.) Diálogos sobre Direito Civil, volume II. Rio de Janeiro: Renovar, 2008; p. 33/60.

NEGREIROS, Teresa. "O princípio da boa-fé contratual", in BODIN DE MORAES, Maria Celina (coord). Princípios do Direito Civil Contemporâneo. Rio de Janeiro: Renovar, 2006; pp. 221/254.

PERLINGIERI, Pietro. II Diritto Civile nella Legalità Costituzionale. Nápoles: Edizioni Scientifiche Italiane, 2001. 1997.

Perfis do Direito Civil: Introdução ao Direito Civil Constitucional. Rio de Janeiro: Renovar,

RODOTÀ, Stefano. La Vita e le Regole: tra diritto e non diritto. Milão: Feltrinelli, 2007.

SANTORO-PASSARELLI, Francisco. Dottrine Generali del Diritto Civile. Nápoles: Jovene, 9ạ ed., 2002.

SCHREIBER, Anderson. Direito Civil Constitucional. São Paulo: Atlas, 2014.

TEPEDINO, Gustavo. "Contornos constitucionais da propriedade privada", in Temas de Direito Civil, vol. I. Rio de Janeiro: Renovar, 2003; p. 267/292.

TRIMARCHI, Pietro. Istituzioni di Diritto Privato. Milão: Giuffrè, 2007.

WU, Tim. Impérios da Comunicação: do telefone à internet, da AT\&T ao Google. Rio de Janeiro: Zahar, 2012. 
Revista de Direito da Cidade

vol. 08, nㅇ 4. ISSN 2317-7721

DOI: $10.12957 /$ rdc.2016.25740

Trabalho enviado em 23 de setembro de 2016.

Aceito em 13 de novembro de 2016.

Revista de Direito da Cidade, vol. 08, no 4. ISSN 2317-7721 pp. 1757- 17771777 